\title{
Off-pump coronary artery bypass grafting: Do it often, do it well, and do it completely-or don't do it at all
}

\author{
Jennifer S. Lawton, MD
}

\author{
From the Division of Cardiac Surgery, Department of Surgery, Johns Hopkins University, Baltimore, Md. \\ Disclosures: Author has nothing to disclose with regard to commercial support. \\ Received for publication June 29, 2016; accepted for publication June 30, 2016; available ahead of print July 30, \\ 2016. \\ Address for reprints: Jennifer S. Lawton, MD, Johns Hopkins University, 1800 Orleans St, Zayed 7101, \\ Baltimore, MD 21287 (E-mail: jlawton4@jhmi.edu). \\ J Thorac Cardiovasc Surg 2016;152:1331-2 \\ $0022-5223 / \$ 36.00$ \\ Copyright (C) 2016 by The American Association for Thoracic Surgery \\ http://dx.doi.org/10.1016/j.jtcvs.2016.07.009
}

Although it is generally accepted that coronary artery bypass grafting $(\mathrm{CABG})$ is preferred to percutaneous coronary intervention in patients with diabetes and multivessel coronary artery disease, ${ }^{1}$ the choice of on-pump versus off-pump CABG remains controversial. ${ }^{2}$ In this issue of the Journal, Benedetto and colleagues ${ }^{3}$ publish a comparison of a large group of patients with diabetes $(\mathrm{N}=2450)$ who underwent isolated, first-time CABG for multivessel disease with either off-pump or on-pump technique at a single center (Bristol Heart Institute) during a 19-year period.

Propensity matching was used, and 995 pairs were compared. There was no difference in early or late mortality between groups; however, morbidity (risk of cerebrovascular accident, postoperative intra-aortic balloon pump placement, and reexploration for bleeding) was reduced in patients undergoing off-pump $\mathrm{CABG}$ relative to those undergoing on-pump CABG.

Unfortunately, little information can be gleaned regarding the benefit of the use of arterial grafts in these patients. The use of bilateral internal thoracic artery grafting was low (only $2.8 \%$ of on-pump and $1.8 \%$ of off-pump procedures), although $42 \%$ of the patients in both groups were obese. Of note, patients undergoing off-pump CABG had higher left internal thoracic artery use $(93 \%)$ and radial artery use $(21.3 \%)$ than those undergoing on-pump CABG, whereas the on-pump group had a higher rate of saphenous vein graft use $(92.5 \%)$. One is thus left wondering whether any longterm benefits derived from more arterial grafting in the offpump group influenced the observed conclusions.

The study is retrospective, with all of the attendant drawbacks (no matter what statistical "hoops" that Benedetto and colleagues ${ }^{3}$ may have jumped through). These include inherent surgeon preference bias for type of procedure chosen, lack of complete data set (cause of death, blood transfusion use, length of stay, pneumonia, prolonged intubation, graft patency, and need for revascularization).

Despite these limitations, Benedetto and colleagues are to be commended for their results. They clearly do off-pump CABG well. Half of the patients in the total group

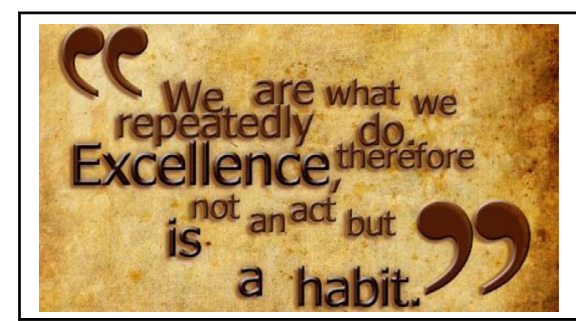

Excellence in off-pump CABG surgery requires practice and complete revascularization. (Interpretation of quotation by Aristotle by Will Durant. Image source: http://rebrandlive.com/strive-for-excellence.)

Central Message

Benedetto and colleagues demonstrate in a large population of patients with diabetes and multivessel CAD that off-pump CABG has morbidity benefits and equivalent survival relative to on-pump CABG.

See Article page 1321.

were operated on with off-pump techniques; a large percentage of patients could be matched $(91 \%$ of off-pump and $96 \%$ of on-pump), suggesting fairly similar groups; and the off-pump surgeons were experienced (conversion to on-pump was only $0.6 \%$ ). Off-pump $\mathrm{CABG}$ is often touted as a technique that benefits high-risk patients the most (women, patients with diabetes, etc), and experienced off-pump surgeons are best equipped to operate on these patients. Similar to other technically demanding procedures for which volume has been shown to influence outcomes, perhaps centers of excellence should be developed for off-pump CABG.

Small, diabetic vessels are often the feature that steers the surgeon away from off-pump techniques or leads the less experienced off-pump surgeon to avoid grafting the smaller vessels. In the study of Benedetto and colleagues, ${ }^{3}$ fewer grafts per patient were performed in the off-pump matched group, and the off-pump group had higher rate of incomplete revascularization than the on-pump group ( $14 \%$ vs $7.4 \%$, respectively). Benedetto and colleagues ${ }^{3}$ noted that off-pump CABG was associated with a $7 \%$ absolute risk of incomplete revascularization, and incomplete revascularization was associated with a nearly $50 \%$ relative risk of increased late mortality.

Thus if you are going to do off-pump CABG, do it often, do it well, and do it completely (graft every ischemic area). With these caveats, the study of Benedetto and colleagues 
would then suggest that morbidity will be reduced and mortality will be equivalent to that with on-pump techniques.

\section{References}

1. Farkouh ME, Domanski M, Sleeper LA, Siami FS, Dangas G, Mack M, et al; FREEDOM Trial Investigators. Strategies for multivessel revascularization in patients with diabetes. N Engl J Med. 2012;367:2375-84.
2. Singh A, Schaff HV, Brooks MM, Hlatky AM, Wisniewski SR, Frye RL, et al; BARI 2D Study Group. On-pump versus off-pump coronary artery bypass graft surgery among patients with type 2 diabetes in the Bypass Angioplasty Revascularization Investigation 2 Diabetes trial. Eur J Cardiothorac Surg. 2016; 49:406-16.

3. Benedetto U, Caputo M, Vohra H, Davies A, Hillier J, Bryan A, et al. Off-pump versus on-pump coronary artery bypass surgery in patients with actively treated diabetes and multivessel coronary disease. J Thorac Cardiovasc Surg. 2016; 152:1321-30.e12. 